\title{
Anesthetic Efficacy Assessment of Two Mental Nerve Block Techniques for Tooth Extraction
}

\author{
Esshagh Lassemi ${ }^{1}$, Mohammad Hosein Kalantar Motamedi ${ }^{*}$ and Zhelia Alemi ${ }^{3}$ \\ ${ }^{1}$ Oral and Maxillofacial Surgery, OMS Dept., Azad Islamic University of Medical Sciences, Tehran, Iran \\ ${ }^{2}$ Oral and Maxillofacial Surgery, Trauma Research Center, Baqiyatallah Medical Sciences University, and Azad University of Medical Sciences, Tehran, Iran \\ ${ }^{3}$ Private Practice Dentistry, Tehran, Iran
}

\begin{abstract}
Background and aim: The mental-incisive nerve block can be used where lower premolars and anterior teeth require treatment. The aim of this study is to compare tow methods ofmental-incisive nerve block for extraction of the lower premolars and anterior teeth.

Methods and materials: This randomized double blind split-mouth clinical trial study was performed on patients requiring extraction of lower premolars and anterior teeth bilaterally. Patients were divided into two groups (case and controls). On one side injection was administered distal to the second premolar while on the other side the injection
\end{abstract} was done between premolars. The teeth were matched in terms of clinical and radiographic features.

Result: 40 patients (80 samples) with a mean age of $50.6 \pm 12.7$ were studied. According to the results, we had a $95 \%$ success rate with injection distal to the second premolar, but the success rate was $72.5 \%$ when the injection was done between premolars.

Conclusion: The mental-incisive nerve block with injection done distal to the second premolar was more successful than between premolars.

Keywords: Anesthesia; Mental - incisive nerve block; Incisors; Premolars; Mandible

\section{Introduction}

The Inferior Alveolar Nerve Block (IANB) is the most important injection technique in dentistry. Unfortunately it also proves to be the most frustrating; with the highest percentage of clinical failure [1]. Potocnik and Bajrovic reported that even when a proper technique is employed, clinical studies show that IANB fails in approximately $30 \%$ to $45 \%$ of cases [2]. Where dental treatment involved procedures on mandibular premolars and anterior teeth incisive nerve block can be administered with greater success [1]. In this study we chose to assess the mental-incisive nerve block (MINB) via 2 techniques where mandibular dental treatment involves bilateral procedures on premolars and anterior teeth [1].

The injection technique for mental-incisive nerve block may influence the success rate. The target is the mental foramen located on external surface of the body of the mandible below the first and second premolars where the IAN divides into terminal incisive and mental branches. The incisive branch continues forward in a bony canal or in a plexiform arrangement, giving off branches to the first premolar, canine and incisor teeth, and the associated labial gingiva. The lower central incisor teeth receive a bilateral innervation, fibers probably crossing the midline within the periosteum to re-enter the bone via numerous canals in the labial cortical plate. The mental nerve passes upward, backward and outward to emerge from the mandible via the mental foramen between and just below the apices of the premolar teeth [3].

The location of mental foramen varies in different people [4-8]; in $24 \%$ of individuals the mental foramen is located distal to the root of the second premolar; in $50 \%$, between the premolars roots, in $20 \%$ to $25 \%$ at the area of the second premolar root and in $1 \%$ to $2 \%$ anterior to the first premolar or mesial to the first molar [8]. These different location may cause problems in obtaining anesthesia $[3,5,8,9]$. There are different methods for MINB; the present study compared 2 mental
- incisive nerve block techniques for the extraction of lower premolars and anterior teeth bilaterally. One method was to inject between the first and second premolar so that the needle passed between the two premolars vertically. In the other method, the injection was performed distal to second premolar.

\section{Patient and Methods}

This was a randomized double blind, split-mouth clinical study. The study was performed on 40 patients ( 80 samples) that referred to the oral and maxillofacial surgery department 2010-2011 for the lower premolars and anterior teeth extraction bilaterally. Patients were divided into two groups (case and control). On one side, injection was done distal to the second premolar and on the other side between premolars [10]. For randomization, (simple random sampling) the patients were injected alternatively; i.e. starting on the right side with injection between premolars and in the next session the opposite side was injected distal to the lower second premolar. In the next patient the first injection was done on the left side distal to the second premolar and in the next session the right side was injected between premolars. This randomizing mode continued to the end of the study. In the case group, the needle penetrated the depth of the vestibule distal to the second premolar using a 27 gauge needle. Entry was from behind the patient at the ten $\mathrm{O}^{\prime}$ clock and the opposite side at the $2 \mathrm{O}^{\prime}$ 'clock position. The needle entered the soft tissue about 5-8 $\mathrm{mm}$ supraperiosteal, with

*Corresponding author: Motamedi MHK, Africa Expressway, Golestan St, Giti Blvd. No.11 Tehran, 19667, Iran, Tel: 0098-21-226-16-946; E-mail: motamedical@yahoo.com

Received June 01, 2013; Accepted July 20, 2013; Published July 27, 2013

Citation: Lassemi E, Kalantar Motamedi MH, Alemi Z (2013) Anesthetic Efficacy Assessment of Two Mental Nerve Block Techniques for Tooth Extraction Anaplastology S6: 003. doi: 10.4172/2161-1173.S6-003

Copyright: ( $) 2013$ Lassemi E, et al. This is an open-access article distributed under the terms of the Creative Commons Attribution License, which permits unrestricted use, distribution, and reproduction in any medium, provided the original author and source are credited. 
mouth half-open and lip and buccal tissues retracted (Figure 1). When standing behind the patient, the anatomical landmarks were the second premolar and buccal vestibule. In the control group an injection was done in the depth of buccal mucosa between two premolars at a depth of 5-6 mm using a 27 gauge needle with the mouth half open [11] (Figure 2). In both groups local anesthetic solution was lidocaine $2 \%$ $(1 \mathrm{cc})$ with epinephrine (1/80000). All patients had a lingual injection $(0.8 \mathrm{cc})$ which was administered $2 \mathrm{~mm}$ distal to the tooth in the floor of the mouth. Extraction was done 5 minutes after injection. Successful injections meant pain free extraction. All injections were done by one operator. Patients and operator were blinded to the study. All patients volunteered for extraction of teeth for orthodontics or provision of full dentures. The teeth were matched in terms of clinical and radiographic features. Mandibular premolar teeth are commonly used as a landmark for finding the location of the mental foramen $[5,6]$. In this study it is not necessary for the needle to enter the mental foramen. Data was statistically analyzed using the chi-square test.

\section{Results}

We assess 40 patients (80 injections) including 23 men and 17 women with mean age of $50.6 \pm 12.7$ who had lower anterior teeth or premolars bilaterally requiring extraction.

Distribution of teeth according to mandibular anterior teeth is presented in Table 1.

Age, gender, number and type of tooth had no influence on the technique, butinjection success rate according to the mental - incisive

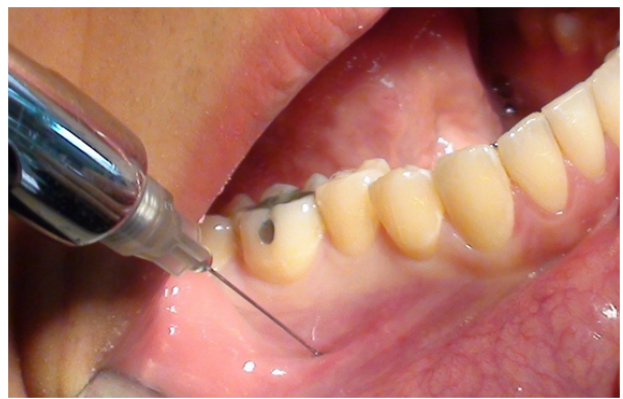

Figure 1: The injection administered distal to the second premolar. The syringe should be from posterior to anterior, from above to below and from lateral to medial.

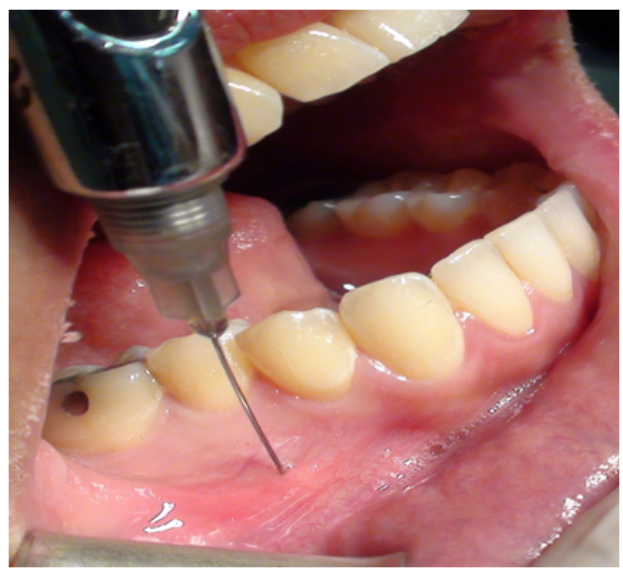

Figure 2: The injection administered in the depth of buccal mucosa between two premolars at a depth of 5-6 mm using a 27 gauge short needle with the mouth half open while standing in front.

\begin{tabular}{|c|c|c|}
\hline Tooth Type & Number & Percentage \\
\hline Central & 22 & 27.5 \\
\hline Lateral & 16 & 20 \\
\hline Canine & 12 & 15 \\
\hline First Premolar & 22 & 27.5 \\
\hline Second Premolar & 8 & 10 \\
\hline Total & 80 & 100 \\
\hline
\end{tabular}

Table 1: Distribution of studied teeth based on tooth type.

\begin{tabular}{|l|c|c|c|}
\hline $\begin{array}{r}\text { Success } \\
\text { Rate }\end{array}$ & Successful & $\begin{array}{c}\text { Non } \\
\text { Successful }\end{array}$ & Total \\
\hline $\begin{array}{l}\text { Injection } \\
\mathrm{N}_{1}=40\end{array}$ & $29(72.5)$ & $11(27.5)$ & $40(100)$ \\
\hline $\begin{array}{l}\text { Needle entrance between premolars } \\
\text { premolar } \mathrm{N}_{2}=40\end{array}$ & $38(95)$ & $2(5)$ & $40(100)$ \\
\hline
\end{tabular}

Table 2: Distribution of success rate on the basis of mental-incisive nerve block technique separately $(P<0.01)$.

nerve block technique separately is represented in Table 2.

The MINB with needle entrance distal to the second premolarhad a 95\% (Figure 1) and MINB with needle entrance between premolars had a $72.5 \%$ success rate respectively. Chi-square test showed that this difference was statistically significant $(p<0.01)$. If mental nerve block injection is administered with the needle entrance between premolars (Figure 2), the chance of failure is greater (R.R=5.5).

\section{Discussion}

Mental - Incisive nerve block can be an alternative of IANB. When dental procedures requiring pulpal anesthesia on mandibular teeth anterior to the mental foramen (e.g. canine to canine or premolar to premolar) are treated, the mental-incisive nerve block is recommended in place of bilateral IANBs [1]. According to the result, we found that MINB with needle penetration distal to second premolar was more effective (95\%) than needle penetration between two premolars (72.5\%). $\mathrm{Al}$ Yasser and $\mathrm{Al} \mathrm{Nwoku} \mathrm{[10]} \mathrm{showed} \mathrm{that} \mathrm{the} \mathrm{mental} \mathrm{foramen} \mathrm{location}$ on both sides of the mandible in $80 \%$ of cases is symmetrical and in $46.2 \%$ of cases the mental foramen is located between the longitudinal axis of the two premolars. Moiseiwitch [5] reported that anteriorposterior positions of mental foramens in most cases are symmetrical. This study showed that in $54 \%$ of cases the mental foramen is located more anterior than the long axis of the second premolar of the mandible and in $35 \%$ of cases at the long axis of the second premolar and in $11 \%$ more posterior than the long axis of the second premolar [5]. In most studies on mental foramens in different cases, researchers reported that most mental foramens are in line with second premolars $[6,9]$. Other researches on different races achieved the same results [6]. It does not seem that anterior-posterior position of mental foramen would be depended on the race [6]. What most scientists agree with is the presence of mental foramen in range of the long axis of the second premolar [5-7]. In regard to its relation to the root, it lies in about $50 \%$ of cases at the level of the root of second premolar, between the two premolars in about $20 \%$ to $25 \%$ and posterior to the second premolar in about $24 \%$, in approximately $1 \%$ to $2 \%$ it lies as forward as the first premolar or as far back as the first molar [8]. This may be why the technique in which the needle penetrates mucosa distal to second premolar may make the success rate of MINB higher. According to the results, the success rate of anesthesia with this study (distal to second premolar) was $95 \%$ and with needle penetration between premolar was $72.5 \%$. The $5 \%$ failure rate pertaining to the central incisors can be 
Citation: Lassemi E, Kalantar Motamedi MH, Alemi Z (2013) Anesthetic Efficacy Assessment of Two Mental Nerve Block Techniques for Tooth Extraction. Anaplastology S6: 003. doi: 10.4172/2161-1173.S6-003

Page 3 of 3

due to the some overlap between the left and right nerve fibers in the midline [1,3]. According to Malamed the correct position of the dentist is in front of the patient so that the syringemay be placed into the mouth below the patients line of sight and the thumb or index finger in the mucobuccal fold against the body of the mandible in the first molar area and moved slowly anteriorlyuntil feeling the bone become irregular and somewhat concave [1] while in our technique there is no need to palpate the area and produce discomfort for patients. Mucosal penetration done from the distal of the second premolar the needle is not in the line of sight of the patient but syringe may be (Figure 1). When standing in front of the patient it is easier for the patient to see the needle whereas when standing behind the patient it is unlikely for him or her to visualize the needle from the corner of the eyes.

\section{Conclusion}

Mental-incisive nerve block with injection distal to the second premolar was more successful than between premolars.

\section{References}

1. Malamed S (2004) Hand book of local anesthesia (5thedn), Mosby Publications, Missouri, USA 14: 228-252.
2. Potocnik I, Bajrovic F (1999) Failure of inferior alveolar nerve block. Endod Dent Traumatol 15: 247-251.

3. Williams D, Bannister L, Berry M (2008) Gray's Anatomy(39thedn) Churchill Livingstone Publications 33: 601.

4. Joyce A, Donnely J (1992) Evaluation of effectiveness and comfort of incisive nerve anesthesia inside or outside the mental foramen. J Endod 18: 409-411.

5. Moiseiwitsch JR (1998) Position of the mental foramen in North American white population. Oral Surg Oral Med Oral Pathol Oral Radiol Endod 85: 457-460.

6. Green R (1987) The Position of the mental foramen: A comparison between the southern Chinese and other ethnic and racial groups. Oral Surg Oral Med Oral Pathol 63: 287-290.

7. Phillips JL, Weller RN, Kulid JC (1992) The mental foramen: Part 3, size and position on panoramic Radiographs, J Endod 18: 383-386.

8. Henry Hollinshead. Anatomy For Surgeons: The Head and Neck. (3rdedn) Harper \& Row, Publishers Philadelphia 1: 538

9. Wesley E Shankland (1994) The position of the Mental Foramen in Asian Indians. J Oral Implantology 20: 118-122.

10. Al Jasser NM, Al Nwoku (1998) Radiographic study of the mental foramen in a selected Saudi population. Dento maxillofacial Radiology 27: 341-343.

11. Sicher H (1970) Oral Anatomy. (5thedn), Mosby Publications, USA, chap 1 : 44-48. 